\title{
Analysis of Friction Factor \& Coefficient Of Friction Using Ring Compression Test under Various Lubricants
}

\author{
Arpit Srivastava, Anurag Shrivastava, Anand Bhushan Mishra
}

\begin{abstract}
The objective of this work is to obtain the friction factor \& coefficient of friction by compressing a small cylindrical Ring under dry and lubricated condition. Friction is very sensitive to the forming process (like forging, drawing, Extrusion, etc.). In this experiment a standard size of cylindrical ring of dimension outer diameter $42 \mathrm{~mm}$, inner diameter $21 \mathrm{~mm}$ and height of $14 \mathrm{~mm}$ is examined under compressive load. This standard dimension is in the ration of 6:3:2 (Outer Diameter: Inner Diameter: Height) which was defined by the MALE \& COCKCRAFT in their experiment. This standard dimension is widely accepted. Aluminum alloy (AA-6101) rod was used for making ring of standard dimension by using Lath machine. These Rings are compressed on Universal Testing Machine under dry condition, servo 2T Diesel oil, Allyl isothiocyanate and Grease. Deformation took place under the influence of load and contact friction in the lateral and longitudinal direction. By substituting the value of change in the inner diameter and chance in the height in the formula given by Male and Depierre, Avitzur, we calculate the friction factor and friction coefficient. Load applied to deform the specimen, is insensitive to friction condition.
\end{abstract}

Index Terms - Ring Compression Test, Aluminum alloy AA6101, Cold Forging, friction factor \& coefficient.

\section{INTRODUCTION}

Friction at the contact surface between the die and work piece is an important variable and it has significant effects on the both the work piece and the process variables such as deformation load metal flow, surface quality and internal structure of material.

Therefore, the interfacial friction should be understood and controlled. Friction is very complex in all the metal forming process. Friction, wear and lubrication mechanism are closely related.

There are many method to analyses the friction factor and coefficient of friction but among all of them Ring compression Test is best suitable and globally accepted.

Ring Compression Test works on the principle of change in the internal diameter of Ring Specimen. When a Ring is compressed, Percentage change in the internal diameter of Ring corresponding to percentage change in the reduction in height of the test specimen, provides the quantitative knowledge of the magnitude of the coefficient of friction at die and work piece work surface.

If the Specimen's internal diameter increases during compression then friction is low and if internal diameter decreases while compression than friction is high. With the help of this relationship a calibration curve was drawn to find

Arpit Srivastava, M.Tech Scholar, SRMIT, Lucknow

Anurag Shrivastava, Head of Department, SRIMT, Lucknow

Anand Bhushan Mishra, M.Tech, SRIMT, Lucknow out the interfacial friction. This is known as Friction Calibration Curve. This curve was generated by Male \& Cockcroft. There results shows the coefficient of friction tended to increase with increasing deformation rate for different metal under dry condition and with a semi solid lubricant. Male and Cockcroft used geometry in the ratio of 6:3:2 (OD: ID: H).

\section{FRICTION}

Friction is defined as the resistance to relative sliding between two bodies in the contact under a normal load. Metal working processes are significantly affected by friction because of the relative motion and the forces present between tools, dies and work pieces. Friction is energy dissipating process (irreversible) that results in the generation of heat. Friction significantly affects the flow and deformation of the materials in the metal forming process. In the metal cutting process it tends to wear the tool and reduces the tool life.

The friction can be controlled by several means. For a particular theory of friction it must explain the frictional behavior of two bodies under a variety of conditions, such as load, relative sliding, speed, temperature, surface condition, and the environment. Coulomb modal of friction states that friction results from the mechanical interlocking of the rough surface asperities, there by requiring some force to be able to slide the two bodies along each other.

\section{A. ADHESION THEORY OF FRICTION}

The adhesion theory of friction is based on the observation that two clean, dry (unlubricated) metal surface (regardless of how smooth they are) contact each other at only fraction of their apparent area of contact. The static load at the interface is thus supported by the contacting asperities. The sum of contacting area is known as the real area of contact.

Under the light load and with the large area of contact, the normal stress is low and hence it is elastic. As we increases the load the stresses increases and eventually the junction undergoes the plastic deformation. Also with increase the load the contact area also increases. Because of the asperity height distribution on the surfaces is random, some junction is in elastic contact and some junction is in the plastic contact. The intimate contact of asperities develops adhesive bond. The nature of this bond involves atomic interaction, mutual solubility and diffusion.

\section{B. COEFFICIENT OF FRICTION}

Sliding between the two bodies under a normal load is only possible when there is a tangential force. According to the adhesive theory $\mathrm{F}$ force is require to shear the junction. The coefficient of friction at the interface is defined as:

$$
\mu=\frac{E}{N}
$$


Friction Factor (m) can be defined as the ration of shear strength and shear yield stress.

\section{WHAT IS RING COMPRESSION TEST}

- In the bulk forming process The Ring Compression Test is the most widely applied method for determining the contact conditions. It is consider as the standard and universal method for determining friction factor and coefficient of friction.

- It is use as the qualitative method for comparing the lubrication condition to influence of various lubricants onto the contact friction in the cold or hot forming process.

- In this method we monitor the change of internal diameter as well as reduction in the height of the ring specimen because change in the dimension shows the sensitivity to the active contact surface.

Friction is determined from the friction calibration chart from the percentage change in the height and by measuring the change in the internal diameter of the specimen.

Figure 1: friction calibration curves
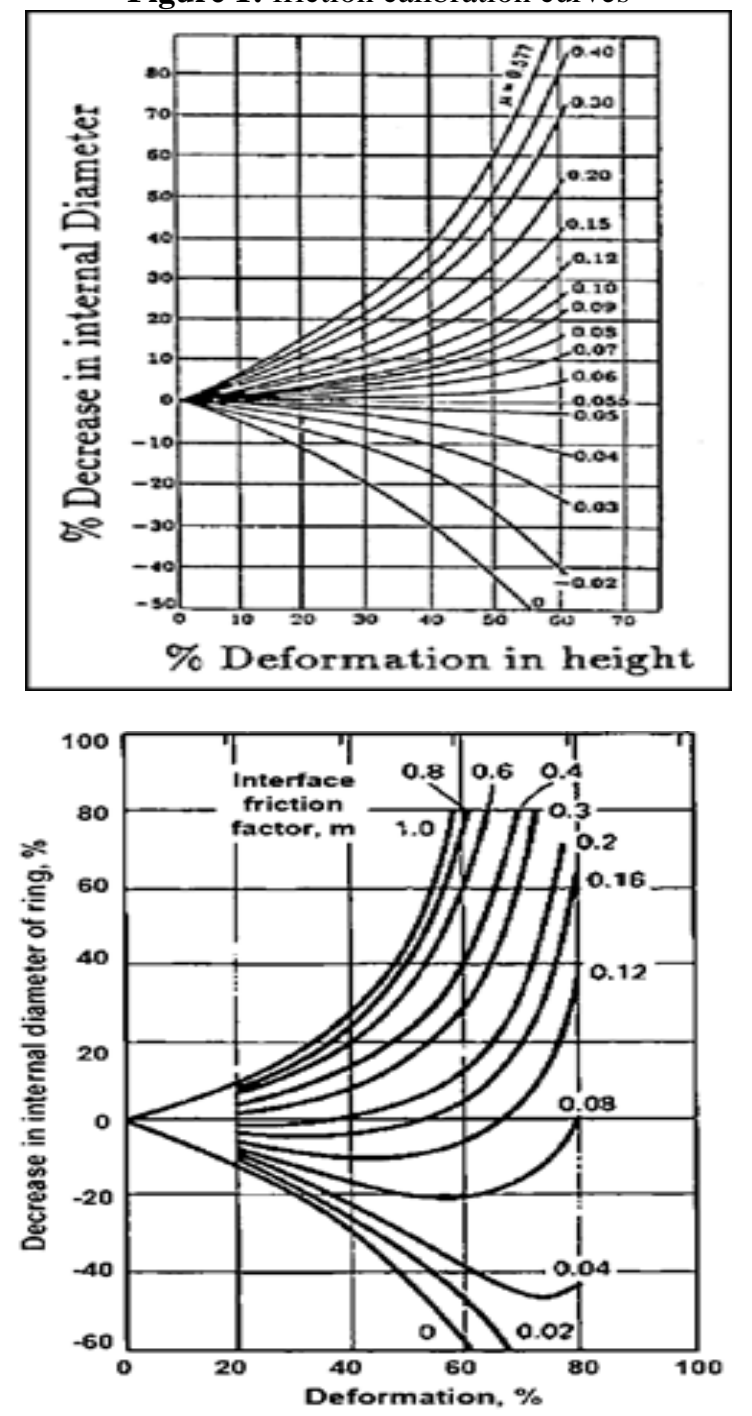

- The above graphs is dependent of height strain and inner strain at various influences of friction, gives calibration curves.

- When a hollow cylinder (small) is compressed axially between the flat, rigid and parallel platens the inner diameter of the ring may increase, decrease or remain constant. It depends upon the amount of the friction present between the contact surfaces.

- Under the zero friction condition the hole size increases proportionately to the outer diameter. And ring compresses as would corresponding portion of the compressed solid cylinder.

- As the friction increases, the rate of expansion of the hole decreases. The compressive hoop stress developed as the hole is sufficient to cause the hole to contract.

- Male and Cockcroft generated the calibration curves by experimental method by assuming $\mu$-friction in inter contact of the ring and tool.

- The initial dimension of the of the ring in the following ratio,

\section{OUTER DIAMETER: INNER DIAMETER: HEIGHT $=6: 3: 2$.}

- This ratio is adopted as standard dimensions in the ring compression test method.

- In this test, a ring specimen is compressed between the flat, parallel tools and the coefficient of friction is determined by the calibration curves by measuring the change in the internal diameter and reduction in the height of the specimen.

- Since it does not require the determination of the load, it has been frequently used for estimation of friction during the forming process without large expansion of a billet surface.

Figure 2: (a) Zero friction (b) Low friction or good lubricant (c) High friction or bad lubrication
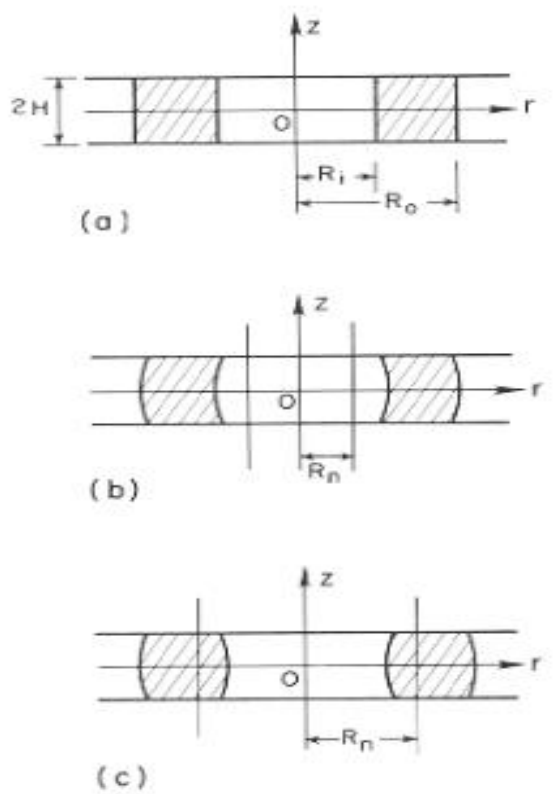

\section{APPLICATION}

- Ring compression test is unique and standard method to determine the effect of friction on the flow of material while deformation process. Basically this method is can only be used in the forging process.

- Friction plays a very significant role in the forging process. Magnitude of load depends on the contact surface.

- In the forging process higher accuracy of dimension can be achieved by optimizing the friction. 
- By comparing the different type of lubricant we can find the better lubricant with optimum friction value.

\section{HISTORY OF RING COMPRESSION TEST}

The ring compression test originated by Kunogi in 1954 and later it was improved and presented by Male and Cockcroft. After Male and Cockcroft published their well known paper, many researchers came in the front for this experiment. Avitzur and Hawkyard and Johnson analyzed a hollow disk theoretically by assuming uniform distortion (i.e. no barreling, no strain hardening and constant interface friction shear factor). Male carried out a study to obtain the variation of friction coefficient of metal during compression. Later again Male investigated the applicability of Ring compression test. Male and DePierre then investigated the validity of constant interface friction shear factor in order to characterize interfacial friction condition during forging on hollow disk.

\section{EFFECT OF FRICTION}

Friction has very significant effect on the forging or forming process. High friction may damage the die and gives the bad surface finish. Due to high friction high value of load required for same $\%$ of reduction in dimension. Even in some case we don't require friction and in some case we can't ignore the friction. So in any of the forming process we need to optimize the friction by using the suitable lubricant.

Selection of the lubricant depends upon the temperature, load, shape of die, process of forming, etc.

Inner radius as well as curvature of inner hole of the Ring specimen change with respect to the friction and lubricity of lubricant. It also depend on the nature of lubricant i.e. lubricant is semi solid or liquid in nature.

\section{A. UNDER DRY CONDITION}

In the dry condition (no lubricant is used), as we applied the load on the ring specimen to perform the test, the height of the ring reduces and the outer radius of the ring increases. But the inner radius may increase or decrease or remain same it totally depend on the contact surface friction.

The friction will be high as compare to the lubricated one so different section have different material flow rate due to sticky and non sticky condition. Due to friction both contact surface have lower material flow rate as compare to the material with no contact.

Figure 3: material flow under compression at high friction

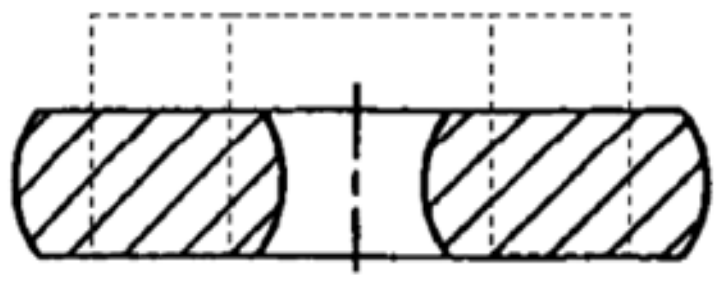

\section{B. UNDER LUBRICATION}

In this test we used three lubricant (1) semi synthetic 2-stroke engine oil (2) Allyl isothiocyanate (Mustard oil) and (3) Grease.

As we paste lubricant on the contact surfaces, the friction reduces. This reduced friction change the flow of the material from earlier one. due to lower friction value the material flow rate of contact surface will be higher as compare to those part of material which is in not in contact.

Figure 4: material flow under low friction

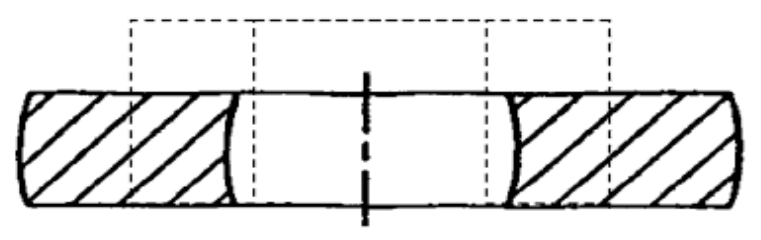

VII. MATERIAL USED

In this experiment we used the aluminum alloy AA6101.

Table 1: \% weight composition in AA6101

\begin{tabular}{|c|c|}
\hline Element & \% weight \\
\hline $\mathrm{Al}$ & 98.90 \\
\hline $\mathrm{Si}$ & 0.50 \\
\hline $\mathrm{Mg}$ & 0.60 \\
\hline
\end{tabular}

Table 2: Properties of AA6101 aluminum alloy

\begin{tabular}{|c|c|c|}
\hline \multicolumn{2}{|c|}{ Properties } & $\begin{array}{c}\text { Temp. } \\
{ }^{\mathbf{0}} \mathbf{C}\end{array}$ \\
\hline Density & $2.7 \times 1000 \mathrm{Kg} / \mathrm{m}^{3}$ & 25 \\
\hline Poisson Ratio & 0.33 & 25 \\
\hline Elastic modlus & $70-80 \mathrm{GPa}$ & 25 \\
\hline Tensile Strength & $97 \mathrm{MPa}$ & 25 \\
\hline Yield Strength & $76 \mathrm{MPa}$ & 25 \\
\hline
\end{tabular}

\section{METHODOLOGY}

- In this Ring Compression Test, a cylindrical rod of aluminum alloy was used which U.S.A. standard code is AA-6101. This raw cylindrical aluminum alloy was manufactured by HINDALCO PVT. LTD. The raw material was of dimension of $54 \mathrm{~mm}$ in diameter. Later this raw cylindrical rod machined by using LATH machine.

- In the turning operation, $54 \mathrm{~mm}$ cylindrical rod was converted in to the 6 piece of Ring plate having standard dimension $(\mathrm{OD}=42 \mathrm{~mm}$; $\mathrm{ID}=21 \mathrm{~mm} ; \mathrm{H}=14)$.

- These Ring's surface was well finished to minimize the surface roughness. And all the components have approximately same surface finish.

Figure 5: Ring Specimen before compression

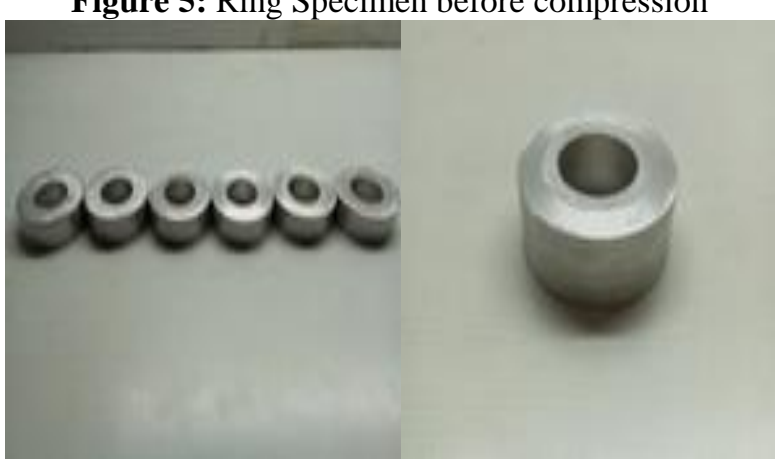


- Now these well finished rings are compressed on the Universal testing machine on various conditions like dry condition and lubrication condition.

- Three lubricants were used during compression in which two was in the liquid form and one was in semi-solid form. These lubricants were servo 2T Diesel oil, Mustard Oil and Grease.

- Before compression these lubricant were simply pasted on the surfaces of ring and dies with the finger tip.

- All this experiment was conducted on the room temperature $33^{\circ} \mathrm{C}$. Ring specimen was not heated in any furnace.

- After compression we got the various dimension of the ring's inner, outer diameter and height at different condition.

- By using below formula we can calculate the friction factor and coefficient of friction at dry and lubricated condition.

$$
\begin{gathered}
m=\frac{-1}{2 \frac{R o}{H}\left(1+\frac{R i}{R o}-2 \frac{R n}{R o}\right)} X \ln \left[\left(\frac{R i}{R o}\right)^{2} X \frac{\left(\frac{R n}{R o}\right)^{2}+\sqrt{3+\left(\frac{R n}{R o}\right)^{4}}}{\left(\frac{R n}{R o}\right)^{2}+\sqrt{3\left(\frac{R i}{R o}\right)^{4}+\left(\frac{R n}{R o}\right)^{2}}}\right] \\
R n=R o \sqrt{\frac{\left(\frac{R i}{R o}\right)+\left(\frac{\Delta R i}{\Delta R o}\right)}{\left(\frac{R o}{R i}\right)+\left(\frac{\Delta R i}{\Delta R o}\right)}} \\
\mu=\frac{m}{\sqrt{3}}
\end{gathered}
$$

Where;

$\mathrm{Ri}$ - Inner radius of specimen after compression

Ro - Outer radius of specimen after compression

$\Delta \mathrm{Ri}$-Chance in internal radius of specimen after compression

$\Delta \mathrm{Ro}$-Change in outer radius of specimen after compression

$\mathrm{H}$-Height of specimen after compression

$\mathrm{m}$-friction factor

$\mu$-coefficient of friction

\section{SPECIMEN AFTER DEFORMATION:}

Figure 6: Ring specimen after compression one dry condition and three lubricated
Dry Condition:
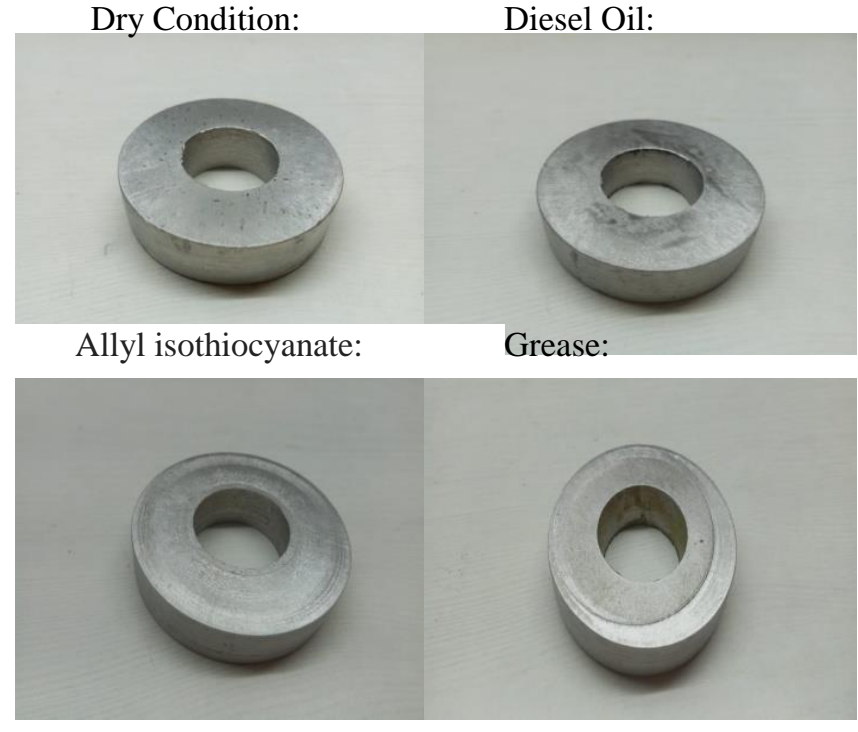

X. RESULTS \& DISCUSSION

Metal forming induces high friction and heat generation between the work pieces and dies surface. The interfacial friction has significant impact on the forging process. It impact the die wear, forming quality, and the deformation loads under both dry and lubricated condition. With the help of lubrication of lubricant we can control the forging quality, accuracy and the wear of die. The lubricity directly determines the interface friction, which directly influence the stresses, forging load and energy.

In this study we determine the coefficient of friction and the friction factor between the contact surfaces under the three conditions one is dry condition and others are lubricated one (Diesel oil, mustard oil and grease).

The result obtained is shown in the table below. From the table below is clear that the interfacial friction varies according to different lubrication condition.

The calibration curve presented by Male and Cockcroft of dimension ration

OD: ID: $H=6: 3: 2$ is used to determine the coefficient of friction.

\begin{tabular}{|c|c|c|c|c|c|c|c|c|c|c|c|}
\hline \multirow{2}{*}{$\begin{array}{l}\text { Lubrication } \\
\text { condition }\end{array}$} & \multirow[t]{2}{*}{ Load } & \multicolumn{3}{|c|}{ Initial Reading } & \multicolumn{3}{|c|}{ Final reading } & \multirow{2}{*}{$\begin{array}{c}\% \\
\text { Reduction } \\
\text { in inner } \\
\text { Diameter }\end{array}$} & \multirow{2}{*}{$\begin{array}{c}\% \\
\text { Reduction } \\
\text { in Height }\end{array}$} & \multirow{2}{*}{$\begin{array}{c}\text { Frictio } \\
\text { n } \\
\text { Factor } \\
(\mathbf{m}) \\
\end{array}$} & \multirow{2}{*}{$\begin{array}{c}\text { Friction } \\
\text { Coefficient } \\
(\mu)\end{array}$} \\
\hline & & $\mathbf{D}_{\mathbf{0}}$ & $\mathbf{D}_{\mathbf{i}}$ & $\mathbf{H}$ & $\mathbf{D}_{\mathbf{0}}$ & $\mathbf{D}_{\mathbf{i}}$ & $\mathbf{H}$ & & & & \\
\hline Dry condition & 45.17 & 45 & 21 & 14 & 45.52 & 20.20 & 11.61 & 3.81 & 17.07 & 0.4 & 0.22 \\
\hline Diesel oil & 45.16 & 42.32 & 21.48 & 14.03 & 46.74 & 21.25 & 10.82 & 1.071 & 22.88 & 0.2 & 0.12 \\
\hline Mustard oil & 45.01 & 42.23 & 21.46 & 14.02 & 47.11 & 21.48 & 10.77 & -0.093 & 23.18 & 0.25 & 0.14 \\
\hline Grease & 45.24 & 42.45 & 21.43 & 14.12 & 46.97 & 21.35 & 11.04 & 0.373 & 21.81 & 0.29 & 0.17 \\
\hline
\end{tabular}

Experimental determination of friction factor

Table 3: Experimental determination of friction factors

\begin{tabular}{|c|c|c|c|c|c|c|c|c|c|}
\hline $\begin{array}{l}\text { Lubricant } \\
\text { condition }\end{array}$ & $\begin{array}{c}\text { Load } \\
\text { (tonne) }\end{array}$ & $\begin{array}{c}\text { Inner } \\
\text { Radius }\left(\mathbf{R}_{\mathbf{i}}\right)\end{array}$ & $\begin{array}{c}\text { Outer } \\
\text { Radius }\left(\mathbf{R}_{\mathbf{0}}\right)\end{array}$ & Height (H) & $\Delta \mathbf{R}_{\mathbf{i}}$ & $\Delta \mathbf{R}_{\mathbf{0}}$ & $\mathbf{R}_{\mathbf{n}}$ & m & $\mu$ \\
\hline Dry condition & 45.17 & 10.10 & 22.76 & 11.61 & -0.4 & 0.26 & 12.45 & 0.6169 & 0.36 \\
\hline Diesel oil & 45.16 & 10.62 & 23.37 & 10.82 & -0.115 & 2.21 & 10.08 & 0.2458 & 0.142 \\
\hline Mustard oil & 45.01 & 10.74 & 23.55 & 10.77 & 0.01 & 2.44 & 10.77 & 0.2821 & 0.163 \\
\hline Grease & 45.24 & 10.67 & 23.48 & 11.04 & -0.04 & 2.26 & 10.83 & 0.2998 & 0.173 \\
\hline
\end{tabular}

Theoretical determination of friction factors:

Table 4: Theoretical determination of friction factors 
International Journal of Engineering and Technical Research (IJETR)

ISSN: 2321-0869 (O) 2454-4698 (P) Volume-9, Issue-6, June 2019

Comparison between theoretical and Experimental Results

Table 5: Comparison between the Theoretical and experimental results

\begin{tabular}{|c|c|c|c|c|c|}
\hline \multirow{2}{*}{$\begin{array}{c}\text { Lubricant } \\
\text { condition }\end{array}$} & Load (tonne) & \multicolumn{2}{|c|}{ Friction factor } & \multicolumn{2}{c|}{ Friction coefficient } \\
\cline { 3 - 6 } & & Exp & The & Exp & The \\
\hline Dry condition & 45.17 & 0.4 & 0.6169 & 0.22 & 0.36 \\
\hline Diesel oil & 45.16 & 0.2 & 0.2458 & 0.12 & 0.142 \\
\hline Mustard oil & 45.01 & 0.25 & 0.2821 & 0.14 & 0.163 \\
\hline Grease & 45.24 & 0.29 & 0.2998 & 0.17 & 0.173 \\
\hline
\end{tabular}

XI. LOAD VS DISPLACEMENT GRAPHS FROM UTM:

Graph 1: Load Vs Displacement Graphs from UTM of one dry and three wet condition

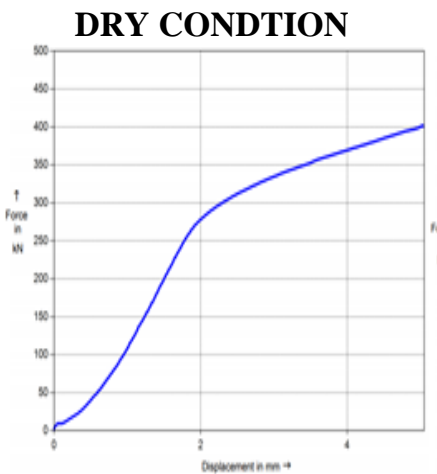

\section{SERVO 2T DIESEL OIL}
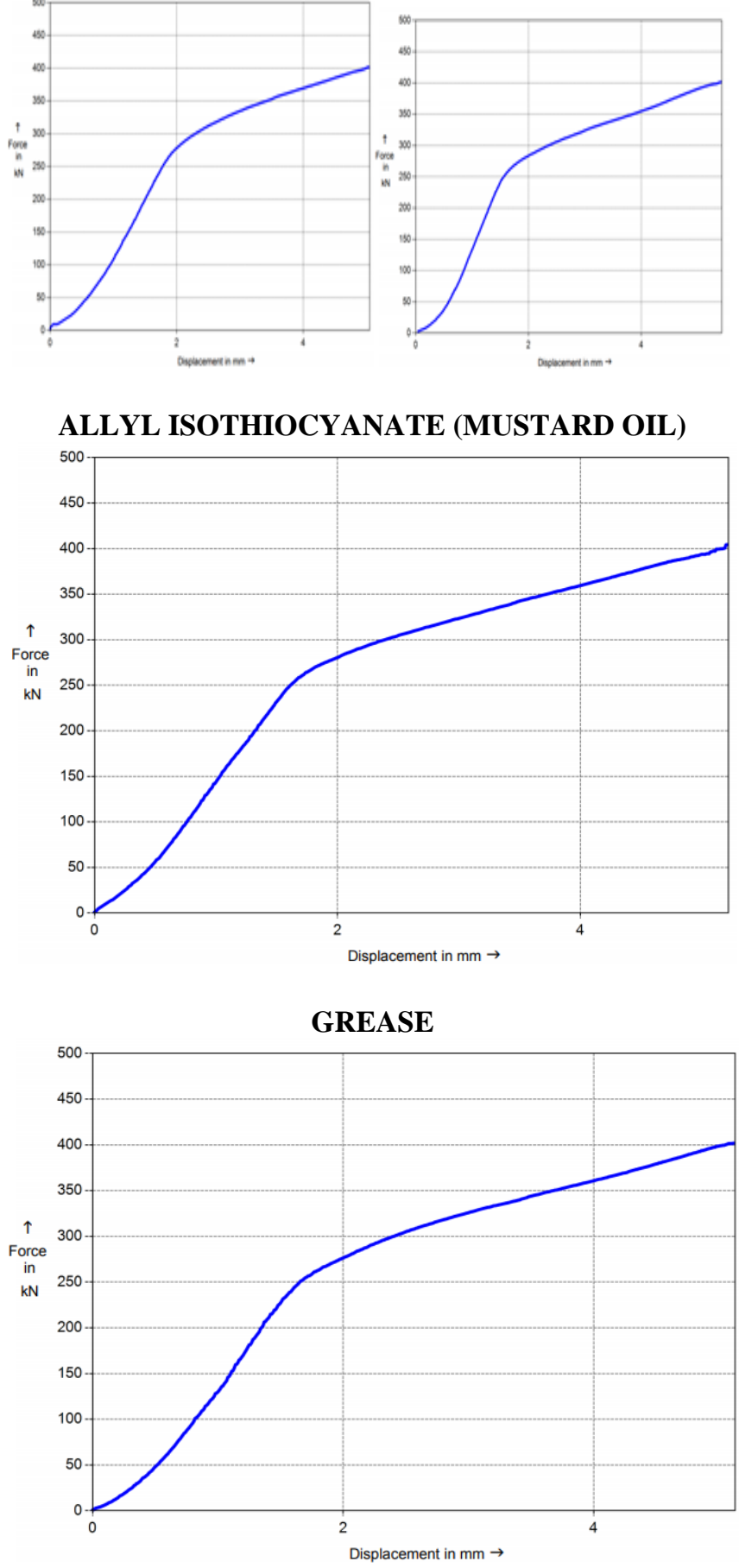

\section{SIMULATION RESULTS}

\section{A. DRY CONDITION}

Figure 7: Simulation on ANSYS 16.0

\section{TOTAL DEFORMATION}

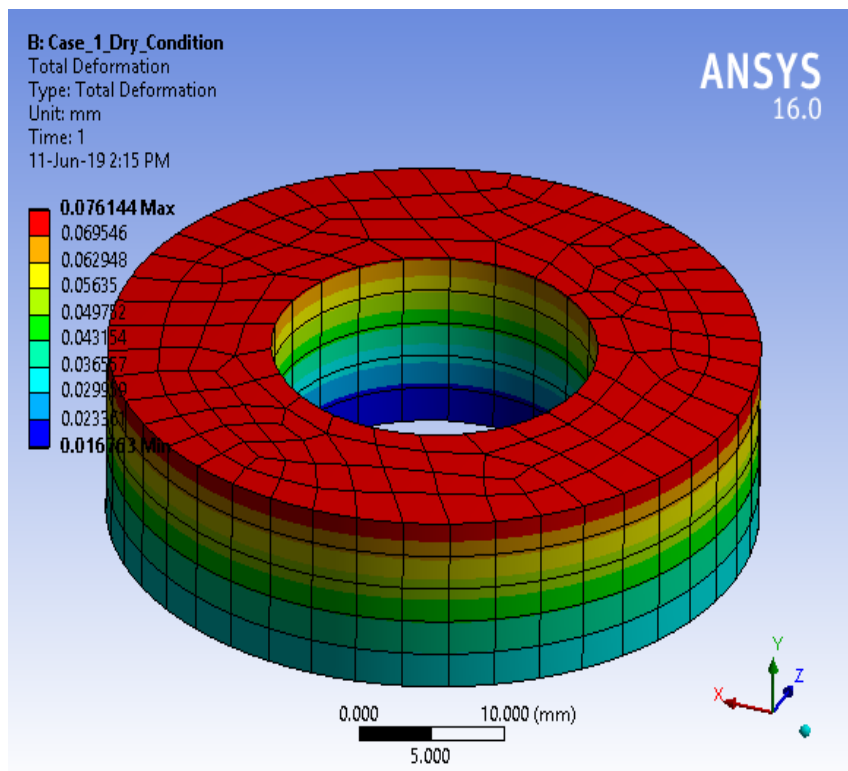

DIRECTIONAL DEFORMATION

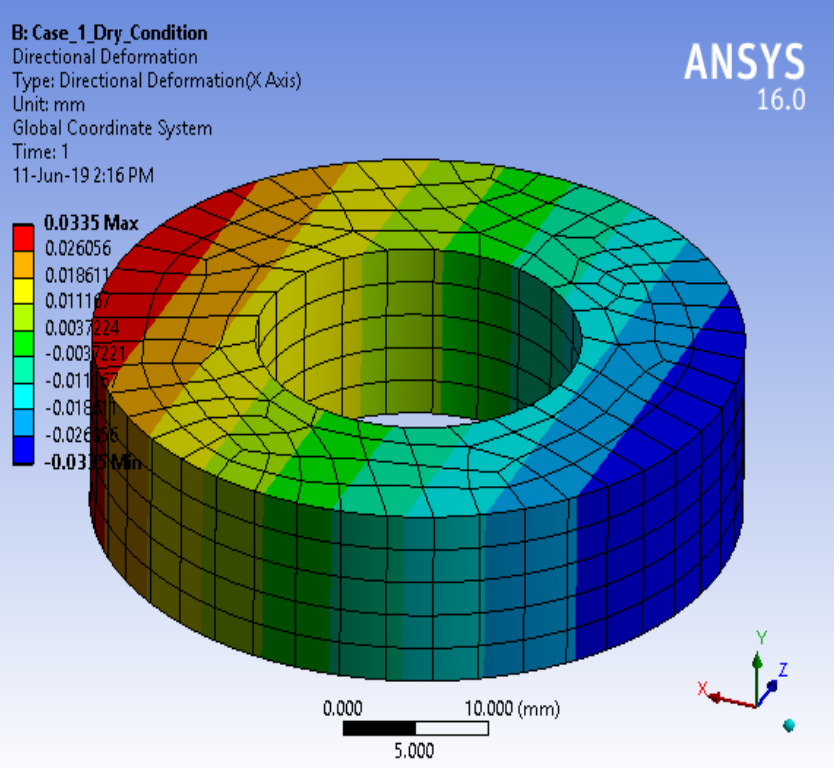




\section{EQUVALENT STRESS}

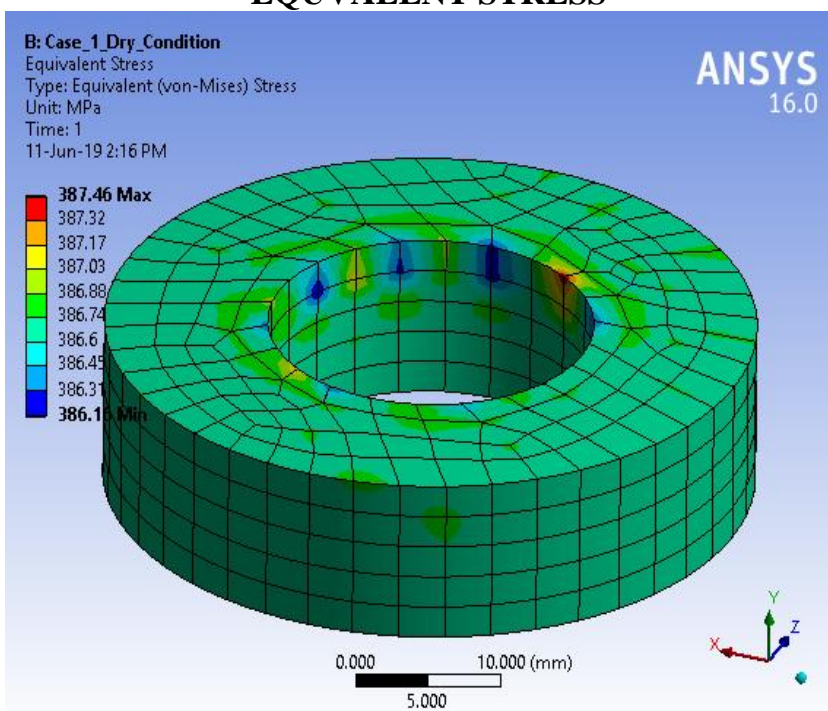

\section{EQUVLENT STRAIN}

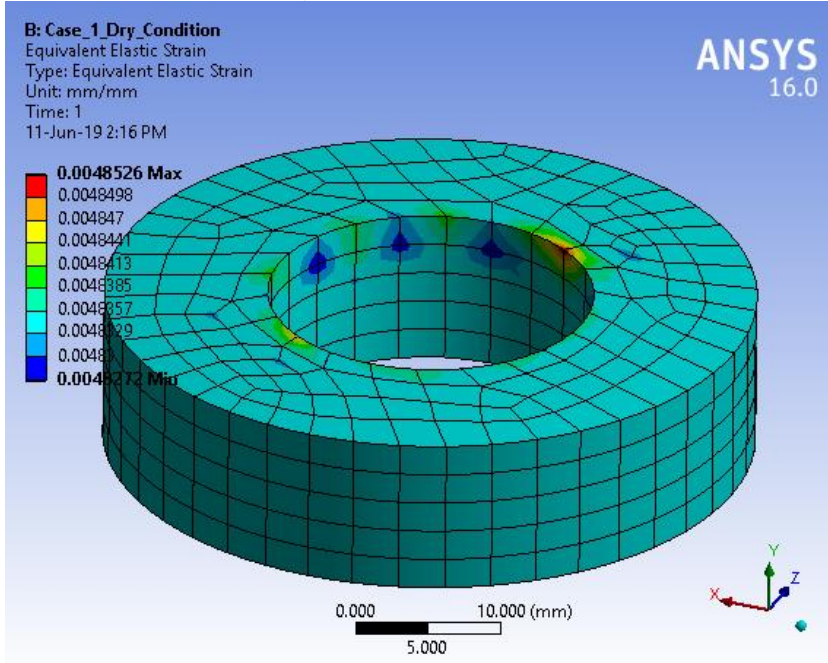

B. SOLID-LIQUID INTERFACE CONDITION

\section{TOTAL DEFORMATION}

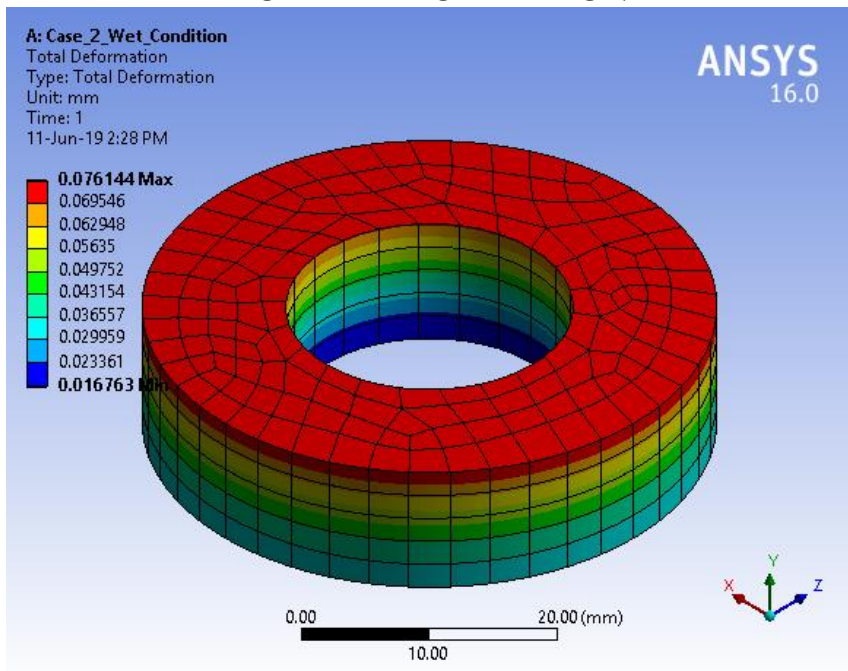

\section{DIRECTIONAL DEFORMATION}

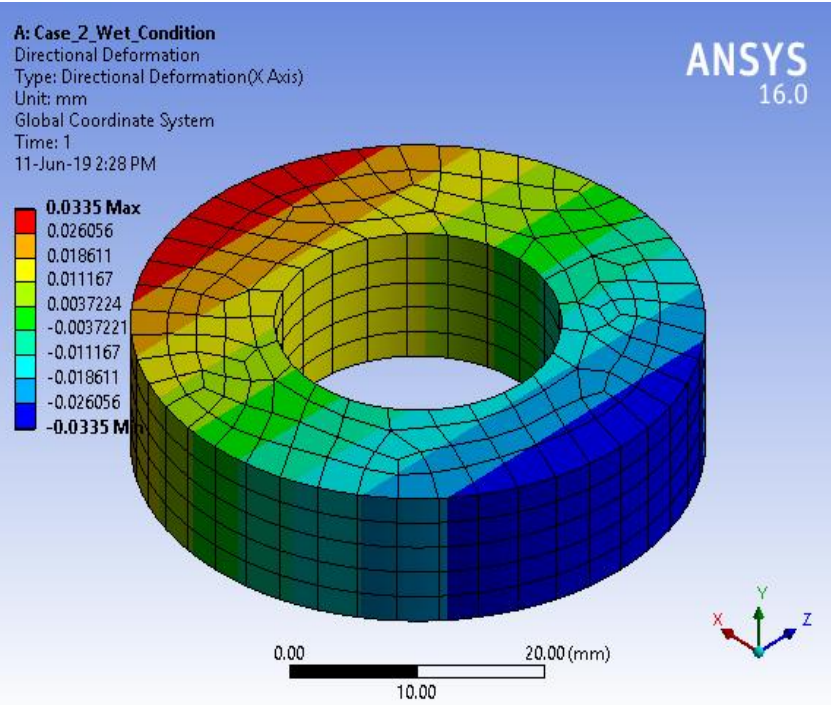

EQUVALENT STRESS

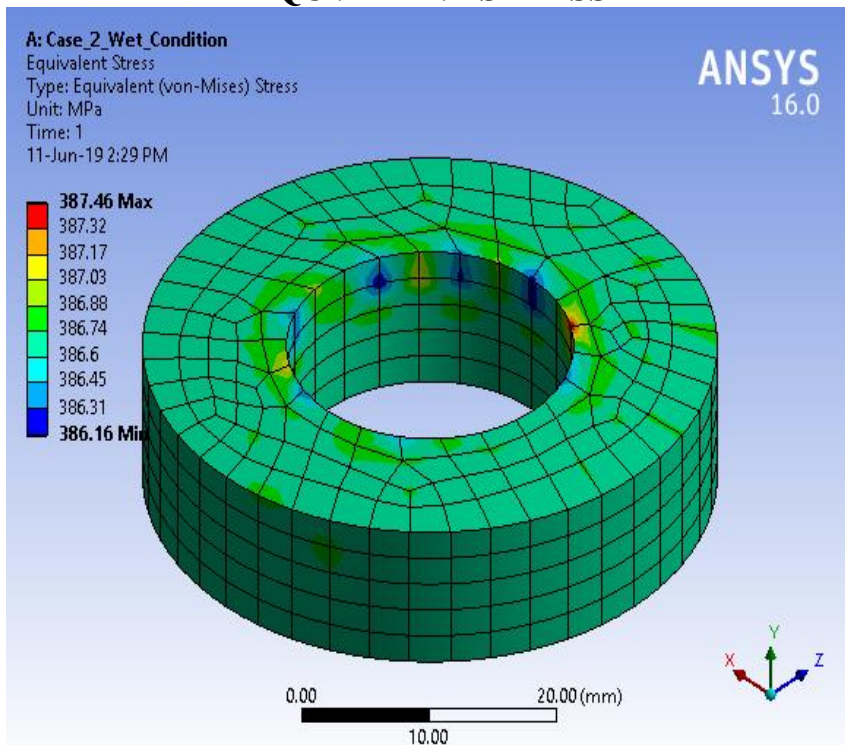

\section{EQUVLENT STRAIN}

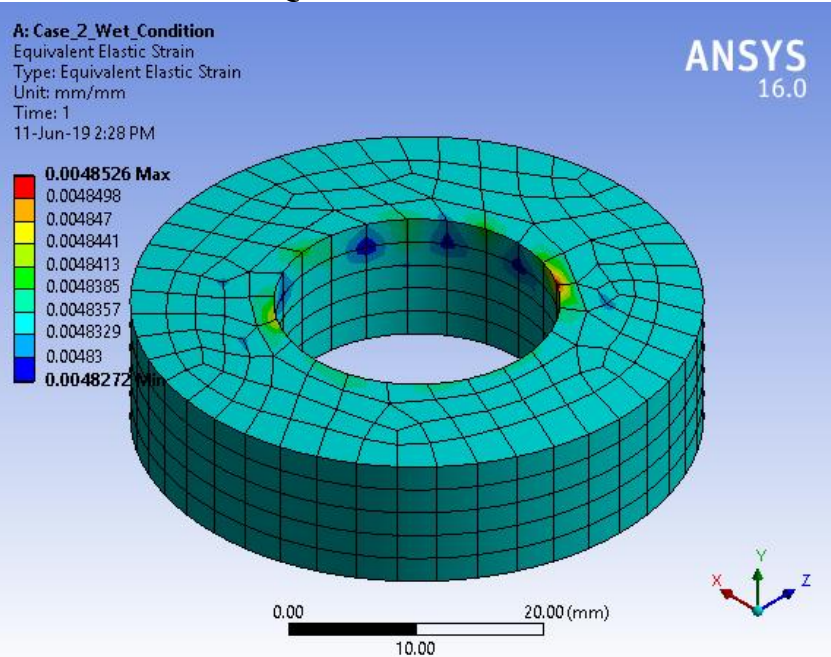




\begin{tabular}{|c|l|l|}
\hline $\begin{array}{l}\text { LUBRICANT } \\
\text { CONDITION }\end{array}$ & $\begin{array}{l}\text { TOTAL } \\
\text { DEFORMATION } \\
(\mathbf{m m})\end{array}$ & $\begin{array}{l}\text { STRESS } \\
\left(\mathbf{N} / \mathbf{m m}^{2}\right)\end{array}$ \\
\hline Dry condition & $\mathbf{0 . 0 7 6}$ & 387.32 \\
\hline $\begin{array}{c}\text { Lubricated } \\
\text { condition }\end{array}$ & $\mathbf{0 . 0 8}$ & $\mathbf{3 8 7 . 4 6}$ \\
\hline
\end{tabular}

Table 6: Simulation Results

In the dry condition we got the total deformation $0.076 \mathrm{~mm}$, Stress $387.32 \mathrm{~N} / \mathrm{mm}^{2}$ where as in the solid liquid interface condition we got the some slightly different value total deformation $0.08 \mathrm{~mm}$ and $387.46 \mathrm{~N} / \mathrm{mm}^{2}$. This results shows that there is higher deformation in the lubricant condition. As shown in table 6.

Graph 2: comparison between theoretical and experimental value of (a) friction factor (b) friction coefficient

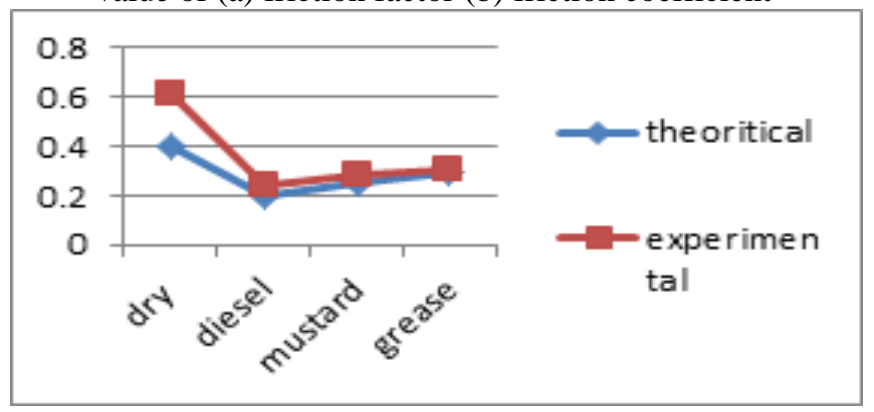

(a)

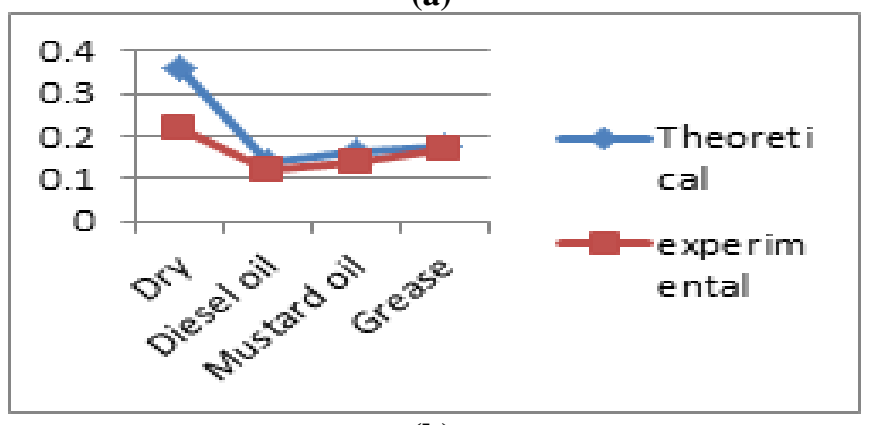

(b)

Above graph shows the comparison between the theoretical and experimental difference in the value of friction factor and friction coefficient.

After all the above experimental, theoritical and simulation analysis we can say that friction have siginificant effect on the forming process. But applied load is insensitive to the deformation. Results od this investigation shows that friction calibration curve is affected by the method of load and friction between the contact surfaces.

\section{CONCLUSION:}

On the basis of above fig we can say that SERVO 2T diesel Oil is better to use in the cold forging process. By using Servo 2T Diesel oil as lubricant we can minimize the friction to the optimum value.

\section{SCOPE:}

- Ring compression test is a standard and widely accepted method for the analysis of interfacial friction during forging. Although there are several method.

- It can be performed on the both cold and hot forging process.

- In the RCT there are too many variations.
- With the help of RCT, we can find out the best lubricant which best suited to the environment and economy.

- It can be performed by changing the various parameters like temp., load, lubricant, etc.

- With the help of RCT we can easily compare the various lubricants as fix parameter.

\section{RFEFRENCES:}

[1] E. Rajesh and M. SivaPrakash; ANALYSIS OF FRICTION FACTOR BY EMPLOYING THE RING COMPRESSION TEST UNDER DIFFERENT LUBRICATION, International Journal and Scientific \& Engineering Research, Volume 4, Issue 5, May 2013.

[2] F. Martin, L.Sevilla, A. Comacho, M.A. Sebastian; UPPER BOUND SOLUTION OF RING COMPRESSION TEST; Department of manufacturing engineering, University of Malaga, Spain. Department of Manufacturing Engineering, National Distance University of Spain (UNED), Madrid, Spain.

[3] F. Martin, M.J. Martin, L. Sevilla, M.A. Sebastian; THE RING COMPRESSION TEST: ANALYSIS OF DIMENTSIONS AND CANONICAL GEOMETRY; Department of manufacturing engineering, University of Malaga, Spain.

[4] J. Valero, M.M. Marin, A.M. Camacho, INFLUENCE OF LOAD APPLICATION METHODOOGY IN THE PERFORMANCE OF RING COMPRESSION TESTS; Department of manufacturing engineering, Univesidad Nacional de Educacion a Distancia (UNED)

[5] MANUFACTURING PROCESSES FOR ENGINEERING MATERIAL by Serope Kalpakjian \& Steven R. Schmid 